\title{
Liberia's Community Health Assistant Program: Scale, Quality, and Resilience
}

\author{
Jessica Healey, ${ }^{a}$ S. Olasford Wiah, ${ }^{b}$ Jannie M. Horace, ${ }^{a}$ Dianah B. Majekodunmi, ${ }^{c}$ Derry S. Duokie ${ }^{b}$
}

\section{Key Messages}

- Liberia's national community health program went from dispersed pilots to nationwide scale within 4 years.

- A network of policy entrepreneurs from the Liberian government, donors, and implementing partners capitalized on several windows of opportunity to achieve this success.

- First, they seized the evidence from a series of pilot projects and-during a point of significant global momentum around community health-evaluated the agenda.

- Second, they leveraged the impact of the community health workers during the Ebola virus disease outbreak to propel forward a consolidated, paid cadre with significant political and financial backing.

- Policy makers and program managers should consider coalition building and identifying diverse champions as an essential ingredient for impacting large-scale change, even in the face of significant challenges.

- Liberia's community health program is bolstered by significant research and evidence. However, the policy entrepreneurs who brought the community leaders, Government of Liberia stakeholders, donors, and partners around the table to buy into a common program has been the "secret sauce" of the program's success.

\section{INTRODUCTION}

L

ibera has weathered significant financial, economic, and social hardship including over a decade of civil war and a year-long outbreak of Ebola virus disease (EVD). Over half of the country lives in poverty. The country's economic situation has been challenged by

\footnotetext{
a Liberia Health Office, U.S. Agency for International Development, Monrovia, Liberia.

${ }^{b}$ Community Health Services Division, Ministry of Health, Monrovia, Liberia.

c International Rescue Committee, Monrovia, Liberia.

Correspondence to Jessica Healey (jhealey@usaid.gov).
}

limited agricultural production and reliance on exports of raw materials, subject to global fluctuations in value. Given these challenges, how did Liberia transition from small-scale community health pilot programs to a government-led nationwide community health assistant (CHA) program in just 4 years?

We argue that this success and the emergence of the community health program as a central pillar of Liberia's health strategy can be attributed to the convergence of ideas, interests, and institutions during significant windows of opportunity in Liberia. This catalytic and unifying change was driven by networks of "policy entrepreneurs"1,2 many of whom-in the Liberian government, among donors, and implementing partners-continue to guide and refine the strategy and program.

An important opportunity presented itself after community health workers were successfully mobilized to respond to the EVD outbreak of 2014-2016, thrusting the community program onto "center stage" in Liberia. During this period, community-based information systems for infectious disease surveillance and response were strengthened and integrated into the community health program. Leaders within the Ministry of Health $(\mathrm{MOH})$, as well as funding and implementing agencies, capitalized on this momentum that led to the harmonized expansion of the program and contributes to the country's ability to respond to the coronavirus disease (COVID-19) pandemic and other health threats as they arise.

\section{THE NATIONAL COMMUNITY HEALTH ASSISTANT PROGRAM}

CHAs are a formal, standardized, and compensated cadre of community health providers. They are supported by community health services supervisors within the community health structures such as community health committees. The CHAs serve as the backbone of the revised national community health services policy and plan for 2016-2021, ${ }^{3}$ which aims to extend the reach of the country's primary health care system to provide a package of essential lifesaving primary health care services and epidemic surveillance within communities and to households on an equitable basis. CHAs-literate men and women who live in the communities they 
serve-are selected by their respective communities. They receive training to deliver an integrated and standardized service delivery package, which includes promotive, preventive, and curative services and epidemic surveillance, to households located more than $5 \mathrm{~km}$ from the nearest health facility (estimated at $29 \%$ of the population as of the last census). CHAs provide health education; test for and treat malaria; provide family planning methods, oral rehydration solution, and zinc; refer pregnant women for antenatal care; assist in mass immunization campaigns; and oversee mass drug administration. Community event-based surveillance of infectious diseases became an important component of CHA training and responsibilities during the EVD outbreak and provided a strong platform for addressing the COVID-19 pandemic response.

By early 2020, the CHA program covered $80 \%$ of all communities outside of the $5 \mathrm{~km}$ radius of a health facility in 14 of the 15 counties of Liberia. ${ }^{4}$ The national report for $2019^{5}$ highlighted the following achievements in the top priority indicators (Table). By June 2021, the CHA program is expected to achieve full county coverage of all targeted communities in all 15 counties. At the time of writing, the program has 3,448 CHAs $(2,862$ male [83\%] and 586 female [17\%] and 373 community health services supervisors (191 male [51\%] and 182 female [49\%]). CHAs have not only expanded the reach of primary care into remote villages but have also contributed to improvements in maternal and child health, as reflected in the 2019/2020 Liberia Demographic and Health Survey that noted a considerable increase in skilled birth attendance and facility deliveries. ${ }^{6}$
For its achievements to revitalize primary health care through the national community health program, Liberia has garnered global recognition, ${ }^{7}$ including being nominated to host the next Global Community Health Symposium. Liberia's new National Community Health Services Policy (2021-2027) is poised to tackle the unfinished agenda focusing on national scale, quality, resilience, and sustainability. Liberia's ambitions and experiences in adapting, innovating, and institutionalizing the national CHA program at national scale can serve as valuable lessons for countries in the midst of boldly redefining and reforming their community health platforms.

\section{FACTORS CONTRIBUTING TO CHA PROGRAM SCALE AND SCOPE}

The CHA program's success was determined by 3 major factors: (1) foundational success with community volunteers through a series of pilots coupled with global momentum, presenting an opportunity for consolidation of policy and programs; (2) emergence of community health workers as the champions of the EVD crisis, presenting another opportunity for large-scale change; and (3) significant leadership from policy entrepreneurs at the community to executive levels who drove change and propelled unity of focus and purpose.

\section{Foundational Success With Community Health Volunteers and Global Momentum}

Like many countries, Liberia's initial focus in community health was largely on malaria, pneumonia, and acute respiratory illness with unpaid

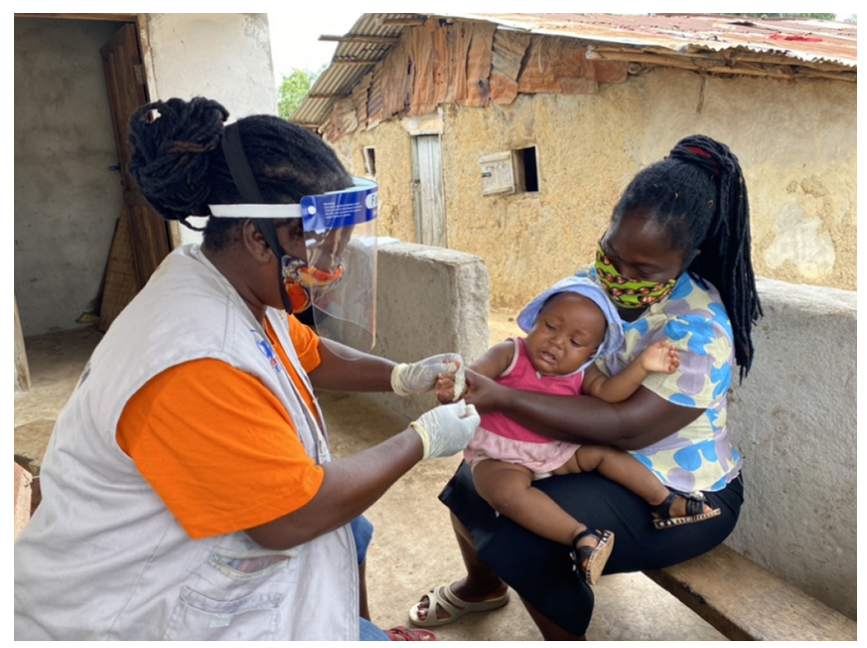

A community health assistant in Suakoko, Bong County, Liberia, conducts a rapid diagnostic test for malaria on a child. () 2020 Jefyne Togba/International Rescue Committee 
TABLE. Achievements of the Community Health Assistants in Liberia, by Indicator, 2019

\begin{tabular}{lcc}
\hline & Target & Achievement \\
\hline $\begin{array}{l}\text { Children under } 5 \text { years of age who tested positive for malaria and treated with } \\
\text { artemisinin-based combination therapy within } 24 \text { hours, \% }\end{array}$ & 60 & 57.7 \\
\hline $\begin{array}{l}\text { Children under } 5 \text { years of age who were diagnosed with pneumonia and treated } \\
\text { with antibiotics, \% }\end{array}$ & 91 & 87.6 \\
\hline $\begin{array}{l}\text { Children under } 5 \text { years of age who were treated for diarrhea with oral rehydration } \\
\text { solution and zinc, \% }\end{array}$ & 87 & 83.3 \\
\hline $\begin{array}{l}\text { Cases treated with appropriate medicine and dose (as confirmed by CHSS during } \\
\text { supervision visits), \% }\end{array}$ & 95 & 87.4 \\
\hline \begin{tabular}{l} 
Pregnant women referred for delivery, no. \\
\hline
\end{tabular} & 22,792 & $19,907^{b}$ \\
\hline
\end{tabular}

Abbreviations: $\mathrm{CHA}$, community health assistant; $\mathrm{CHSS}$, community health services supervisor.

a Reporting rate for community health assistant was $91 \%$.

b $42 \%$ of the total expected pregnant women in the community health assistant population area.

The CHA program, established in 2016, is expected to achieve $100 \%$ coverage of all targeted communities by June 2021. volunteers, called general community health volunteers (gCHVs). The implementation was through various models supported by different partners, some that aligned with the 2011-2015 policy $^{8}$ and focused more squarely on integrated community case management (iCCM) and some that explicitly went beyond the bounds of the current policy (e.g., offered remuneration for gCHVs). ${ }^{9}$ These pilots produced largely robust, positive results and demonstrated that lay community members with basic training and supervision could deliver information, testing, and referrals for malaria, pneumonia, and diarrhea.

The Minister of Health at the time, the Honorable Dr. Walter T. Gwenegale, visited a remote pilot site in Grand Gedeh County and contributed to the momentum and leadership behind the 2010 version of the community health policy that included a harmonized iCCM training, gCHV treatment registers, and the initial tools for the community health information system. As early as 2011, Dr. Gwenegale coauthored an article suggesting that ${ }^{10}$ :

The iCCM pilots laid
a foundation to
develop a scalable
model for
engaging
communities in
primary health
care systems
through
strengthening and
reestablishing
community
governance
structures.

a substantial rural health delivery gap remains, but it could be bridged with a robust cadre of community health workers integrated into the primary health care system.

Building on this early program infrastructure, 4 partners (Africare, EQUIP, International Rescue Committee, and Child Fund) received $\mathrm{MOH}$ approval for their proposals to expand the pilot phase in Gbarpolu, Lofa, Nimba, and Bong counties. The pilot trained 114 gCHVs in 93 catchment communities. These iCCM pilots laid a foundation to develop a scalable model for engaging communities in primary health care systems through strengthening and reestablishing community governance structures (such as the community health committees) and the introduction of a community health workforce (Box 1). The pilots also revealed key challenges and deficiencies in design that influenced the future policy. Some of these critical challenges were related to training length and scope, incentives and tools, supply chain, and health systems functions and reporting.

In 2015, Liberia finalized its Community Health Roadmap, which was an important coalition building process in its own right, bringing in 100 participants from 50 organizations, government, and nongovernmental programs, including the $\mathrm{MOH}$ departments, county health team representatives, United Nations agencies, bilateral and donor agencies, and local and international nongovernmental organizations. The roadmap began addressing the major components of the future policy, including standardized incentives, a draft service package, and integration across other systems, and paved the way for many of the "policy entrepreneurs" to further network and solidify ideas and aspirations for the program.

This early work built on global momentum to prioritize community health emanating from the global campaign, led by Jeffrey Sachs, for 1 million community health workers by 2015 , which was helpful for bringing the international community squarely to the table. ${ }^{11}$

\section{Emergence of Paid Community Health Workers as the Champions of the EVD Crisis}

By the height of the EVD epidemic in 2014, the $\mathrm{MOH}$ changed its strategy from a largely top- 
BOX 1. Spotlight on Current Director of the Ministry of Health Community Health Services Division Mr. S. Olasford Wiah, co-author and Director of the Ministry of Health Community Health Services Division, recalled a period when he was the HIV/TB focal person in River Gee County as the turning point in his career. One of his patients with HIV, who lived in a remote village and to whom he was particularly close, died along with her baby after prolonged labor. At that time and during that period of grief, he learned about the integrated community case management pilots and was appointed as County Community Health Department Director. That is when he decided to focus on community health and "do all it takes to strengthen local community structures." He noted, "I strongly believe that if there was a community health worker in that village, my patient would be alive today." Mr. Wiah has since been a driving force behind the scale-up of the community health assistant program. down, directive approach that was not achieving results to a bottom-up approach, engaging more with the communities to listen and find solutions. The approach utilized the governance system at the subnational level to consult with local leaders including chiefs, traditional leaders, and other community groups and employed multimedia strategies to address traditional practices that were putting people at risk.

Although development partners came to consensus on how to engage communities through local structures and gCHVs, there was no common guidance on tools and incentives. Development partners introduced incentives at varying amounts to social mobilizers, community engagement officers, and contact tracers. By the end of the outbreak, it became clear that with an appropriate motivation package and adequate supervision, CHVs could deliver quality services. It also became clear that the various proposed incentives, tools, and approaches were creating inflated expectations and some chaos within the community health program. It was widely seen as not feasible to revert to a voluntary system or one with ad hoc, limited supervision.

The success of CHVs who supported social mobilization, community engagement, and contact tracing during the EVD crisis were lauded at the highest levels. In her remarks at a U.S. Senate Foreign Relations Subcommittee Hearing, President Ellen Johnson Sirleaf stated ${ }^{12}$ :

I could not agree more about building local capacity. Our 10-year health workforce plan is about building capacity at all levels, particularly at the bottom. It's like a pyramid. We will train ... community health workers to provide basic services ... we are going to make the final push to fight Ebola now by supporting community workers to get the job done.

This support provided an opening for the new community health program and CHAs to be institutionalized, with common training, deployment tools, and supervision structures (Box 2).

By the close of 2015, the previous policy was coming to an end. After a global review, the $\mathrm{MOH}$ arrived at paying the CHAs US\$70 monthly. The new National Community Health Services Strategic Plan 2016-2021 institutionalized the CHAs and their community health services supervisors. ${ }^{3}$ As the EVD outbreak ended, a new policy was launched, reflecting Liberia's vision for a stronger role for communities in the primary health care system by including paid and supervised CHAs, community governance structures, and a communitybased information system. ${ }^{13}$

\section{Strong Leadership From Policy Entrepreneurs}

Without the unrelenting leadership from communities to the highest levels of the national government, the national CHA program could not have been harmonized, scaled up, and continually adapted for quality and sustainability through changing administrations. During the pilot process and earlier periods, Mr. Tamba Boima, Director of the $\mathrm{MOH}$ Community Health Services Division during the EVD outbreak, catalyzed early successes of the pilot and built on the political leadership of Liberia's Minister of Health and President to bring the technical components and partners together in a common plan. By highlighting community health as a flagship program, President Sirleaf paved the way for significant $\mathrm{MOH}$ support from donors and development partners.

As the program was developing, the MOH-led orientation and advocacy meetings with heads of ministries and agencies (ministries of youth and sports, internal affairs, gender, and child protection, etc.), county superintendents, and district commissioners gained widespread buy-in from political and traditional leaders. This leadership continues to bring diverse partners together, providing a platform for focus, financial, and

\section{The new community health policy was launched, reflecting Liberia's vision for a stronger community role in the primary health care system by including paid and supervised CHAs.}



force behind the consolidation of many community health volunteer programs into the community health assistant program. During the early stages of the Ebola virus disease outbreak in 2014-2015, Dr. Dahn coordinated the national response to the epidemic. Upon establishment of the incident management system, she focused on community-based initiatives and restoration of routine health care services. Community health services was at the center of this effort to mobilize communities to restore and rebuild trust in the health system. Under the leadership of Mr. Tamba Boima, Director of the Ministry of Health $(\mathrm{MOH})$ Community Health Services at the time, the $\mathrm{MOH}$ led several community engagement and dialogue sessions with community leaders and catchment communities and service providers. These sessions informed national stakeholders about the many resources and solutions available at the community level and provided lessons on how to promote partnerships with these communities for future outbreaks.

MOH leadership
across all levels
that sought
integration of core
health services
and systems into
the community
health program
was important
and likely
bolstered the
program's
longevity and
resilience in the
face of political
and country
changes.

technical support. These partners included U.S. Agency for International Development (USAID), the World Bank, Last Mile Health, United Nations Children's Fund (UNICEF), Partners In Health, Samaritan's Purse, Co-Impact, and the Global Fund. The significance of this number of funding partners and the investment in a common program cannot be overstated.

Although there were central figures who drove the overall program implementation, the leadership across the $\mathrm{MOH}$ from national to subnational levels that pursued the intentional integration of core health services and systems with the community health program was equally important and likely bolstered the program's longevity and resilience in the face of political and country changes. For example, the new community health program was integrated into human resource guidelines, information systems, supply chain protocols, and the country's research agenda. The MOH leaders' actions to intentionally integrate the program created more government ownership of the program, made it less of a temporary "donor" program, and made the program more resilient to future changes.

The current Director of the MOH Community Health Services Division, S. Olasford Wiah, has maintained this momentum and focus by conducting routine reviews, forming a $\mathrm{MOH}-$ led steering committee, and developing a new "One County, One Partner" 2020 plan* that ensures each county's

The CHA program is widely viewed as a realistic entry point for other innovative work being introduced in Liberia. donors and direction through the One County, One Partner plan enabled gradual scale-up in 14 of the 15 counties toward full coverage.

\section{FUTURE FOR COMMUNITY HEALTH IN LIBERIA}

Across Liberia, CHAs and CHVs play a pivotal role in supporting the national health system and now the COVID-19 response effort, especially in rural communities and in intercounty border communities where access to facility-based health services is limited. The dynamic partnership between health donors and the $\mathrm{MOH}$ to support a truly nationwide, harmonized, national CHA program steered by strong leadership and regular reviews brings health closer to the Liberian people. Today, the CHA program is widely viewed as a realistic entry point for other innovative work being introduced in Liberia including Sayana Press, a uniject family planning method, mental health services, and treatment for severe malaria among young children before referral.

Nevertheless, significant challenges remain. Variations between implementation in different counties due to different partners remains, despite having a harmonized plan and policy. The supply chain challenges that plague the overall health system also impact commodities and supplies for CHAs and represent a significant bottleneck to overall implementation. Supervision structures are frequently weak, which hampers the quality of care provided. Routine changes with payment and support for the CHAs due to funding gaps or other challenges continue. ${ }^{5}$

One significant future challenge is that the CHA program depends almost entirely on donor funding. Even though some salary support from the government is in place, the program cannot

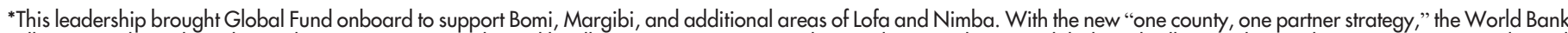

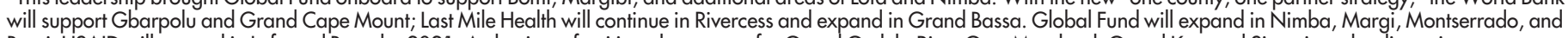
Bomi. USAID will expand in Lofa and Bong by 2021 . At the time of writing, the support for Grand Gedeh, River Gee, Maryland, Grand Kru, and Sinoe is under discussion. 
provide sufficient training and supervision. The program has held together and grown stronger through several different donor funding cycles. The World Bank, UNICEF, USAID, and the Global Fund all went through new strategy processes and made new funding decisions within the past year; all maintained or increased their support for the CHA program.

However, this external support is not a guarantee. Stakeholders and the $\mathrm{MOH}$ routinely express a need to increase domestic funding to ensure the sustainability of this important program, but with Liberia's limited fiscal space, it is unlikely this is on the immediate horizon. Liberia will have to think creatively about sustainability beyond full financial coverage. This could involve graduating communities from the program that have reached a certain level of program achievement or integrating resource mobilization strategies into the CHA program.

Another challenge is the harmonization and integration of the gCHV program for service delivery within $5 \mathrm{~km}$ into the overall national strategic plan. More than a third of Liberia's population lives in urban centers that have different but significant health needs. The MOH is advocating for a CHA approach within these urban centers to address the needs and maximize the efficient use of resources for a clearly defined, singular program.

Critical to overcoming these challenges is renewing and expanding political support across the government and down to the community level for the CHA program, particularly as leadership changes. Some of the new political leadership is not aware of the long history and buy-in for the community health program and see it as a "donor activity." Without strong domestic political support, the national CHA Program is in a precarious position to garner greater financial support from the Government of Liberia and to maintain donor commitment.

In November 2021, Liberia will host the next Global Community Health Symposium. The $\mathrm{MOH}$, its partners, and supporters are planning internal advocacy in advance of the symposium to improve this buy-in and rekindle the broad commitment. This provides an important opportunity for Liberia to share its lessons learned with other countries and to gain insights from other country programs. It also provides the program in Liberia with an important opportunity to further bolster the political engagement, particularly among leaders outside the $\mathrm{MOH}$, with the CHA concept and the critical role the community health program plays in the health sector.

Ebola and then COVID-19 illustrated the power and resilience of frontline workers to adapt in the face of new needs and challenges. New diseases will continue to plague both Liberia and the world. All eyes must remain on those communitybased workers as the foundation of our health system for maternal and child health services and for epidemic preparedness.

Acknowledgments: The community health assistants who bring counsel, diagnostics, medicine, and supplies to their communities and the leaders who stood behind the program provide the inspiration to tell Liberia's story. A special thanks to the leadership of the Ministry of Health and our financial and technical partners in the community health assistant program in Liberia who have banded together through changes and challenges and continue to adapt and push forward. Another special thanks to Nan Chen of Last Mile Health for valuable feedback and guidance as well as input from the Liberia Global Exemplars publication.

Funding: The U.S. Agency for International Development (USAID) funds support the community health assistant program through several partners including International Rescue Committee and Last Mile Health. The views and opinions of authors expressed herein do not necessarily state or reflect those of the U.S. Government or the USAID.

Competing interests: None declared.

\section{REFERENCES}

1. Kingdon JW. Agendas, Alternatives, and Public Policies. 2nd ed. Harper Collins; 2003.

2. Béland D, Katapally TR. Shaping policy change in population health: policy entrepreneurs, ideas, and institutions. Int J Health Policy Manag. 2018;7(5):369-373. CrossRef. Medline

3. Republic of Liberia. Ministry of Health (MOH). The National Community Health Services Strategic Plan 2016-2021. MOH; 2015.

4. Republic of Liberia. Ministry of Health. National community health assistant program: national dashboard.

5. Republic of Liberia. Ministry of Health $(\mathrm{MOH})$. Community Health Services Division. Community Health Services 2019 Annual Report. $\mathrm{MOH} ; 2020$

6. Liberia Institute of Statistics and Geo-Information Services (LISGIS), Ministry of Health and Social Welfare (MOHSW), Republic of Liberia, ICF. Liberia Demographic and Health Survey 2019-20 Key Indicators Report. LISGIS, MOHSW, ICF; 2020. Accessed September 26, 2020. https://dhsprogram.com/pubs/pdf/PR 1 17/PR 1 17.pdf

7. Republic of Liberia. Ministry of Health (MOH). Revised National Community Health Services Strategy and Plan 2011-2015. December 2011. MOH; 2011. Accessed January 25, 2021 https://www.advancingpartners.org/sites/default/files/liberia national_community_health_services_strategy_plan_201 1-2015. docx

8. Exemplars in Global Health. Community health workers in Liberia. Accessed September 29, 2020. https://www.exemplars.health/ topics/community-health-workers/liberia

\section{Critical to overcoming the future challenges to sustaining the CHA program's success is renewing and expanding political support across the government and down to the community level.}


9. Luckow PW, Kenny A, White E, et al. Implementation research on community health workers' provision of maternal and child health services in rural Liberia. Bull World Health Organ. 2017; 95(2): 113-120. CrossRef. Medline

10. Lee PT, Kruse GR, Chan BT, et al. An analysis of Liberia's 2007 national health policy: lessons for health systems strengthening and chronic disease care in poor, post-conflict countries. Global Health. 2011;7:37. CrossRef. Medline

11. Singh $P$, Sachs JD. 1 million community health workers in subSaharan Africa by 2015. Lancet. 382(9889):363-365. CrossRef. Medline
12. Remarks by H.E. Ellen Johnson Sirleaf, President of Liberia to the U.S. Senate Foreign Relations Committee Subcommittee on African Affairs Hearing. December 10, 2014. Accessed September 12, 2020. https://www.emansion.gov.lr/doc/Remarks_By\%20EJS_\% 20US_SFCA_Hearing.pdf

13. Jallah $W$, Kateh F, Panjabi R. Paying and investing in last-mile community health workers accelerates universal health coverage. The BMJ Opinion blog. Published May 22, 2018. Accessed September 29, 2020. https://blogs.bmi.com/bmi/2018/05/22/paying-andinvesting-in-last-mile-community-health-workers-acceleratesuniversal-health-coverage/

\section{Peer Reviewed}

Received: September 29, 2020; Accepted: January 18, 2021

Cite this article as: Healey J, Wiah SO, Horace JM, Majekodunmi DB, Duokie DS. Liberia's community health assistant program: scale, quality, and resilience. Glob Health Sci Pract. 2021;9(Suppl 1):S18-S24. https://doi.org/10.9745/GHSP-D-20-00509

(C) Healey et al. This is an open-access article distributed under the terms of the Creative Commons Attribution 4.0 International License (CC BY 4.0), which permits unrestricted use, distribution, and reproduction in any medium, provided the original author and source are properly cited. To view a copy of the license, visit http:// creativecommons.org/licenses/by/4.0/. When linking to this article, please use the following permanent link: https:// doi.org/10.9745/GHSP-D-20-00509 